\title{
Million International Units per Milliliter
}

National Cancer Institute

\section{Source}

National Cancer Institute. Million International Units per Milliliter. NCI Thesaurus. Code C98757.

A unit of measurement equal to 10 to one million international units of an entity per unit of volume equal to one milliliter. 